\title{
Transient Cold Flow Simulation of Fast-Fluidized Bed Air Reactor with Hematite as an Oxygen Carrier for Chemical Looping Combustion
}

\author{
Pulkit Kumar ${ }^{1}$, Ajit K. Parwani ${ }^{1, *(\mathbb{D})}$, Dileep Kumar Gupta ${ }^{1, *}$ and Vivek Vitankar ${ }^{2}$ \\ 1 Department of Mechanical and Aero-Space Engineering, Institute of Infrastructure, Technology, Research and \\ Management, Ahmedabad 380026, India; pulkit.kumar.17pm@iitram.ac.in \\ 2 Director, FluiDimensions, Pune 411045, India; vivek@fluidimensions.com \\ * Correspondence: ajitkumar.parwani@iitram.ac.in (A.K.P.); dileepkumar@iitram.ac.in (D.K.G.)
}

Citation: Kumar, P.; Parwani, A.K.; Gupta, D.K.; Vitankar, V. Transient Cold Flow Simulation of

Fast-Fluidized Bed Air Reactor with Hematite as an Oxygen Carrier for Chemical Looping Combustion. Appl. Sci. 2021, 11, 2288. https://doi.org/ 10.3390/app11052288

Academic Editor: Dibyendu Sarkar

Received: 2 January 2021

Accepted: 24 February 2021

Published: 5 March 2021

Publisher's Note: MDPI stays neutral with regard to jurisdictional claims in published maps and institutional affiliations.

Copyright: (c) 2021 by the authors. Licensee MDPI, Basel, Switzerland. This article is an open access article distributed under the terms and conditions of the Creative Commons Attribution (CC BY) license (https:// creativecommons.org/licenses/by/ $4.0 /)$.

\begin{abstract}
Chemical looping combustion (CLC) is the most reliable carbon capture technology for curtailing $\mathrm{CO}_{2}$ insertion into the atmosphere. This paper presents the cold flow simulation results necessary to understand the hydrodynamic viability of the fast-fluidized bed air reactor. Hematite is selected as an oxygen carrier due to its easy availability and active nature during the reactions. The dense discrete phase model (DDPM) approach using the commercial software Ansys Fluent is applied in the simulation. An accurate and stable solution is achieved using the second-order upwind numerical scheme. A pressure difference of $150 \mathrm{kPa}$ is obtained between the outlet and inlet of the selected air reactor, which is necessary for the movement of the particle. The stable circulating rate of hematite is achieved after $28 \mathrm{~s}$ of particle injection inside the air reactor. The results have been validated from the experimental results taken from the literature.
\end{abstract}

Keywords: chemical looping combustion; cold flow simulation; hydrodynamic study; hematite; oxygen carriers; DDPM; economic analysis

\section{Introduction}

Carbon dioxide $\left(\mathrm{CO}_{2}\right)$ accumulation in the atmosphere, from different sources, is a serious global concern. Global mean temperatures are rising much faster and if the rate of $\mathrm{CO}_{2}$ emission remains the same for the coming years, then the problem of global warming will increase exponentially. According to the Mauna loa observatory, Hawaii [1], which tracks the $\mathrm{CO}_{2}$ presence in the atmosphere daily, the concentration of $\mathrm{CO}_{2}$ in the atmosphere was determined to be $415.52 \mathrm{ppm}$ in January 2021. This value is far more than 280 ppm, which is the safest level according to climate scientists.

The majority of $\mathrm{CO}_{2}$ emissions are generated by coal-fired power plants, steel and iron industries, cement industries, and automobiles. In a developing nation like India, the backbone of the power sector is coal, which contributes to $55.65 \%$ of the total installed capacity [2]. Therefore, our primary focus should be to reduce the emissions from coal-fired thermal power plants.

Although many technologies have already been developed to reduce emissions, such as integrated gasification combined cycle (IGCC) and ultra-supercritical boilers, due to the energy penalty and high initial investment cost of these technologies, their implementation on large scale is economically not feasible. Carbon capture and storage (CCS) is one of the most reliable solutions to cut this increasing rate of $\mathrm{CO}_{2}$ to the safest level. At least $90 \%$ of emissions from the world's largest sources can be captured by this technology [3,4]. CCS is a three-stage process in which $\mathrm{CO}_{2}$ is captured from the sources first, and then it is transported to a suitable geological site, where it can be stored for a long time. The technologies used in CCS are well known to the world now, but their implementation on a large scale is still not achieved due to the high energy penalty associated with them. On 
the other hand, the implementation of CCS on a large scale is very important in order to fully develop a sustainable energy system in the future. Chemical looping combustion (CLC) is a modified oxy-fuel combustion technique that is highly efficient and inexpensive as compared to other techniques.

The CLC system consists of two interconnected fluidized bed reactors, which are a (1) fuel reactor and (2) an air reactor, as shown in Figure 1. The fuel reactor operates as a bubbling bed and the air reactor operates in a fast fluidization regime. In the CLC process, air and fuel (coal) do not directly mix or react. The oxygen required for the combustion of coal is provided by a metal oxide $\left(\mathrm{Me}_{\mathrm{x}} \mathrm{O}_{\mathrm{y}}\right)$, which is also called an oxygen carrier (OC). These OCs are continuously circulated from the air reactor to the fuel reactor. In the air reactor, OC is oxidized by the air, while in the fuel reactor, the OC supplies oxygen for the combustion of the fuel. In this way, this process loop continues [5]. The products of this combustion reaction are $\mathrm{CO}_{2}$ and steam. It is possible to isolate the steam from $\mathrm{CO}_{2}$ by cooling and condensation.

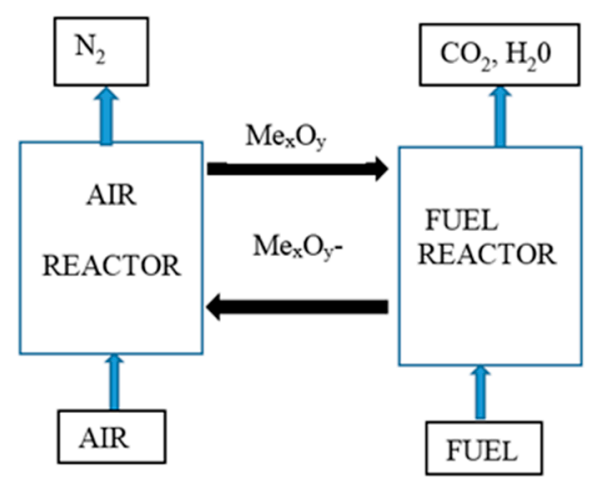

Figure 1. Conceptual diagram of CLC.

The reactions [6] which took place inside the fuel reactor and the air reactor, respectively, are

$$
\begin{gathered}
\text { Fuel }+\mathrm{nMe}_{\mathrm{x}} \mathrm{O}_{\mathrm{y}} \rightarrow \mathrm{nMe}_{\mathrm{x}} \mathrm{Oy}-1+\mathrm{H}_{2} \mathrm{O}+\mathrm{CO}_{2} \\
\mathrm{Me}_{\mathrm{x}} \mathrm{O}_{\mathrm{y}-1}+\frac{1}{2} \mathrm{O}_{2} \rightarrow \mathrm{Me}_{\mathrm{x}} \mathrm{O}_{\mathrm{y}}
\end{gathered}
$$

where $\mathrm{m}$ and $\mathrm{n}$ are the numbers of moles of the reactants and the products. Since the ignition of fuel in the fuel reactor takes place without air, only oxygen is utilized for the combustion, which is given by the OC. The vent stream from the fuel reactor is not polluted or weakened by different gases, for example, nitrogen. This gives a high-virtue $\mathrm{CO}_{2}$ stream, accessible to retrieve at the fuel reactor outlet without the requirement of an energy-expensive process for separation. The only energy cost associated with CLC is the separation of $\mathrm{OC}$ from ash.

OC is the most important part of the CLC technique. The ideal OC should be highly reactive. It should immediately oxidize in the air reactor, as well as reduce in the fuel reactor for good combustion efficiency. It should also be stable, and show good resistance towards fragmentation and attrition. In addition, it should have good fluidization properties so that it does not agglomerate. The materials that can be used for OC are copper, nickel, manganese and iron oxides, but these are not limited, as other elements have also been developed [7]. Several numerical studies have described the reduction and oxidation behavior of oxygen carriers [8-13].

Various researchers have performed simulations on CLC using different OCs [14-21]. Deng et al. [14] developed a reaction kinetic model of a fuel reactor using a mixed OC of calcium sulphate and hydrogen $\left(\mathrm{CaSO}_{4}+\mathrm{H}_{2}\right)$. The computational result showed a low fuel conversion rate with this OC. Arjmand et al. [20] evaluated the performances of different manganese ores as OCs for CLC. They found that the high char conversion rate of manganese makes it a good choice as an OC. Menon and Patnaikuni [21] simulated 
the fuel reactor to compare the performances of two OCs, namely, ferric oxide $\left(\mathrm{Fe}_{2} \mathrm{O}_{3}\right)$ and copper oxide $(\mathrm{CuO})$, as regards the interaction between particle and particle, and fluid and particle, and the reaction rates. They found that $\mathrm{CuO}$ has a better performance when the ash agglomeration effect is not considered, and $\mathrm{Fe}_{2} \mathrm{O}_{3}$ performed better when the ash agglomeration effect was considered. Haider et al. [22] experimentally investigated the cold flow performance of a dual circulating fluidized bed system to understand the hydrodynamic behavior of a pilot-scale advanced $\mathrm{CO}_{2}$ capture technology (PACT) facility at Cranfield, UK. FE100 and molochite were used as the OC. They have concluded that both the risers share similar pressure and density profiles. The circulation rate of OC can be changed by altering the fluidization velocity and bed inventory. However, a stable circulation rate was achieved using pneumatic transport.

CFD modeling techniques and the fundamental equations used in the development of the CFD models have been reviewed by Singh et al. [23]. Shuai et al. [24] developed a 2D CFD model for CLC using inter-connected fluidized beds. They used an Eulerian continuum and two fluid models for both the gas phase and the solid phase. Using their model, they successfully described the hydrodynamics of gas and solid particles in the CLC process. Recently, Hamidouche et al. [25] performed a numerical simulation using the multi-phase particle-in-cell (MP-PIC) method for a biomass-fueled CLC. They found that the fluidization velocity of the air reactor greatly affects the hydrodynamic behavior. Based on their results, they also stated that the pressure balance is very important in order to minimize the gas leakage from the reactor.

From the above discussion of the literature, it can be concluded that in the development of CLC, various researchers have opted for computational approaches to study various parameters in the operation of CLC. The computational approach mainly consists of CFDbased simulation, numerical simulation, thermodynamic computation, ASPEN Plus-based simulation, the DSMC model, the direct simulation Monte Carlo method, etc., to model the process and to study the behavior resulting from variations in design and operating parameters [26]. During their research, various OCs have been investigated, but the cold flow simulation of an air reactor using hematite as the OC has not been performed. In this work, a numerical investigation using the cold flow simulation of the air reactor is performed to understand the hydrodynamic behavior of the system. The hydrodynamic study of the CLC reactors is very crucial in order to analyze the circulation of OC, the interaction among the particles, the pressure drop across the system, and the overall configuration of the system. Hematite, which is an ore of iron, is selected as OC. Iron is readily available, and its low cost makes it an attractive option for OC. In addition, its active nature of being easily oxidized and reduced during the reaction is an added benefit. The simulation results are validated with the experimental results performed by Haider et al. [22] at Cranfield, UK. For this, FE100 is considered as the OC, and the variations in static pressure at different heights of the air reactor are compared.

\section{Materials and Methods}

Ansys Fluent 17.2 was chosen for carrying out the simulation process on a six-core Intel Xenon CPU. The geometry of the air reactor is shown in Figure 2. It is a similar geometry to that used in the experimental work performed by Haider et al. [22]. The air is chosen as the primary phase and hematite as the secondary phase. Since two phases are involved in the simulation, the multiphase modeling approach is used. The Eulerian or dense discrete phase model (DDPM) approach is found suitable according to the gas-solid interaction flow regime in the granular form [27]. For each phase, the continuity and momentum equations are solved. The coupling of particles is achieved through pressure and interphase coefficients. The transient multiphase model is solved using the phasecoupled SIMPLE algorithm. It solves the momentum equation of both the phases in an isolated manner. Since the nature of these equations is highly coupled, it also considers some correction factors to solve the shared pressure and volume fraction between the two phases. The governing equations used in this simulation are described next. 


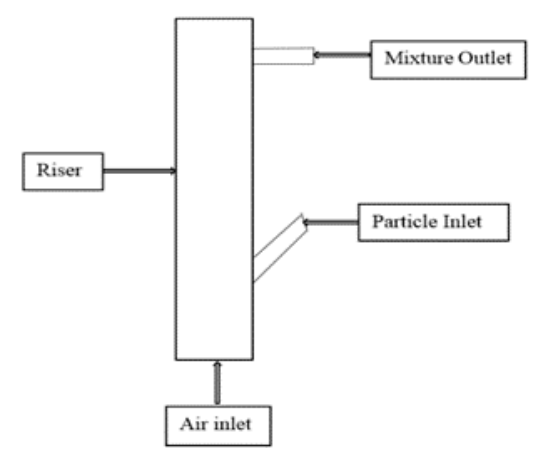

Figure 2. The geometry of the air reactor, similar to the experimental setup of Haider et al. [22].

\subsection{Continuity Equation}

The volume fraction is solved using the following equation [27]:

$$
\begin{gathered}
\mathrm{V}_{\mathrm{Z}}=\int_{\mathrm{v}} \alpha_{\mathrm{Z}} \mathrm{dv} \\
\sum_{\mathrm{Z}=1}^{\mathrm{n}} \alpha_{\mathrm{z}}=1 \\
\hat{\rho}_{\mathrm{z}}=\alpha_{\mathrm{z}} \rho_{\mathrm{z}}
\end{gathered}
$$

where $V_{z}=$ volume, $\alpha_{z}=$ volume fraction, $\rho_{z}=$ density and $\hat{\rho}_{z}=$ effective density of each phase.

\subsection{Momentum Equation}

The conservation of momentum equation for gas (fluid) is solved by the following equation

$$
\frac{\partial\left(\alpha_{\mathrm{f}} \rho_{\mathrm{f}} \mathrm{u}_{\mathrm{f}}\right)}{\partial \mathrm{t}}+\nabla \cdot\left(\alpha_{\mathrm{f}} \rho_{\mathrm{f}} \mathrm{u}_{\mathrm{f}} \mathrm{u}_{\mathrm{f}}\right)=-\alpha_{\mathrm{f}} \nabla \mathrm{p}_{\mathrm{f}}-\nabla \cdot \tau_{\mathrm{f}}+\alpha_{\mathrm{f}} \rho_{\mathrm{f}} \mathrm{g}-\mathrm{R}_{\mathrm{sg}}
$$

where $\mathrm{p}_{\mathrm{f}}=$ pressure of fluid, $\tau_{\mathrm{f}}=$ shear stress of fluid, $\mathrm{u}_{\mathrm{f}}=$ velocity of the fluid phase, $\mathrm{g}=$ acceleration due to gravity and $R_{\mathrm{sg}}=$ momentum transfer from the fluid to the solid [28].

Similarly, the momentum equation used for the solid phase to define the trajectory of particles is given by

$$
\frac{\partial\left(u_{s}\right)}{\partial t}=g \frac{\left(\rho_{f}-\rho_{s}\right)}{\rho_{s}}+F_{D}\left(u_{f}-u_{s}\right)+F_{K T G F}
$$

The terms on the right-hand side in Equation (7) are forces due to gravity, interphase drag, and particle-particle collisions, respectively. Here, $\mathrm{F}_{\mathrm{D}}$ is the drag coefficient given by the following equation [28]:

$$
F_{D}=\frac{18 \mu_{f} R_{p} C_{D}}{\rho_{P} d_{p}^{2} 24}
$$

where $C_{D}$ is the coefficient of drag, $d_{p}$ is particle diameter, and $e_{p}$ represents the Reynolds number, which is given by [28]

$$
\operatorname{Re}_{\mathrm{p}}=\frac{\mathrm{p}_{\mathrm{f}} \mathrm{d}_{\mathrm{p}}\left|\mathrm{u}_{\mathrm{f}}-\mathrm{u}_{\mathrm{p}}\right|}{\mu_{\mathrm{f}}}
$$

The interaction between the phases is defined using the Syamlal and O'Brien model [29]. This model is significant in characterizing the motion of particles in a fluidized bed because 
it corrects the terminal velocity, which is the minimum velocity required for lifting the particle so that it can move outside the bed.

$$
C_{D}=\left((0.63)+\frac{4.8}{\sqrt{\frac{\mathrm{Re}_{\mathrm{p}}}{\mathrm{V}_{\mathrm{r}, \mathrm{P}}}}}\right)^{2}
$$

where $V_{r, P}$ is the terminal velocity correction factor, which is given by

$$
\mathrm{V}_{\mathrm{r}, \mathrm{P}}=0.5\left(\mathrm{~A}-0.06 \operatorname{Re}_{\mathrm{p}}+\sqrt{\left(0.06 \operatorname{Re}_{\mathrm{p}}\right)^{2}+0.12 \operatorname{Re}_{\mathrm{p}}(2 \mathrm{~B}-\mathrm{A})+\mathrm{A}^{2}}\right)
$$

where $A=\propto_{f}^{4.14}$ and $B=\left\{0.8 \alpha_{f}^{1.28}\right.$ if $\alpha_{f} \leq 0.85, \propto_{f}^{2.65}$ if $\left.\alpha_{f}>0.85\right\}$.

The force due to the collision of the particle is obtained by the particle pressure, which is obtained by the kinetic theory of granular flows (KTGF), given by [28]

$$
\mathrm{F}_{\mathrm{KTGF}}=-\nabla \cdot \tau_{\mathrm{s}}
$$

\section{Results}

The geometry of the air reactor considered in this simulation is taken to be similar to that in the experimental work of Haider et al. [22]. The height of the riser is $7.3 \mathrm{~m}$, with an interior diameter of $0.1 \mathrm{~m}$, while the diameter of the inlet and outlet pipes is $0.04 \mathrm{~m}$. Figure $3 a, b$ show the mesh generated on the upper and lower parts of the computational domain. Figure $3 c$ shows the top view of the mesh. The grid size with the mesh count of 516,332 elements is found to be optimum. At the inlet and outlet of the particles, the meshing is coarse because of the maximum number of interactions between the particles. In the current simulation, hematite is chosen as the OC with a particle diameter of $60 \mu \mathrm{m}$ and a density of $5150 \mathrm{~kg} / \mathrm{m}^{3}$. Simulation is done to understand the distribution of the pressure and volume fraction of particles at different bed heights. During simulation, the solid mass flow circulation is kept constant, considering the experimental conditions. An accurate and stable solution is achieved using the second-order upwind numerical scheme. For injection purposes, the standard parcel release method is used [30,31].

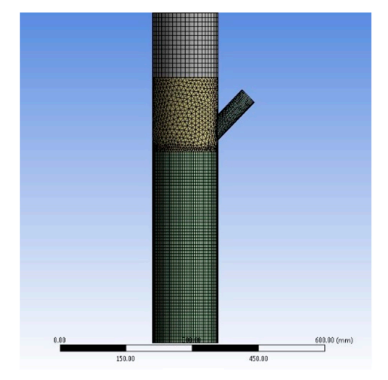

(a)

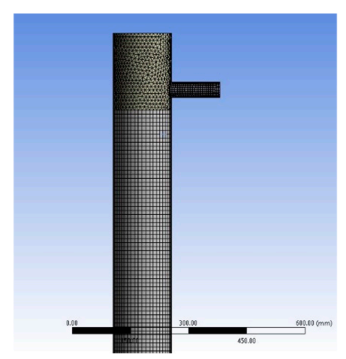

(b)

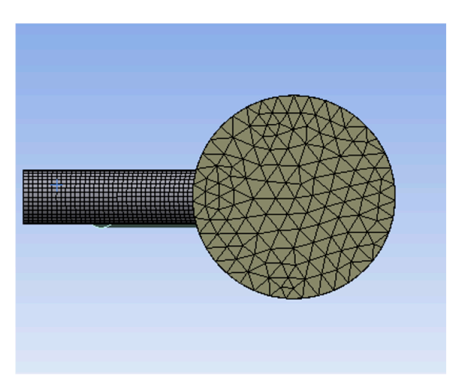

(c)

Figure 3. Mesh in the (a) upper part and (b) lower part; (C) top view of the air. 
Initially, the inlet velocity of the air from the bottom and the velocity of the injection of the OC is taken as zero. The injection of OC occurs at the particle inlet for $1 \mathrm{~s}$ only and almost 198,565 particles are released. The velocity of the air is maintained at zero for the next second so that the particle that falls due to gravitation settles down at the bottom, and its kinetic energy becomes negligible. This is the initial boundary condition of the simulation. After the bed of $\mathrm{OC}$ is formed, the inlet velocity of the air is increased gradually up to $2.50 \mathrm{~m} / \mathrm{s}$, which is slightly greater than the minimum fluidization velocity for the particle [22]. This velocity is supposed to lift the particle outside the reactor towards the mixture outlet. When the air velocity is increased, the particles in the settled bed experience sudden lift force, and they begin to move upward. Particles that are at the top of the bed reach the outlet of the reactor at around $15 \mathrm{~s}$. The whole simulation runs for almost 45 days due to the large number of particles. The results of the simulation are monitored at different heights, i.e., $0 \mathrm{~m}$ (air inlet), $0.5 \mathrm{~m}, 0.75 \mathrm{~m}, 6 \mathrm{~m}, 7 \mathrm{~m}$, and mixture outlet. The mass flow rate of the particle is set as $0.04 \mathrm{~kg} / \mathrm{s}$, similar to the solid circulation rate of Haider et al. [22]. Various other key modeling parameters required to run the simulation are given in Table 1.

Table 1. Modeling parameters considered for simulation.

\begin{tabular}{ll}
\hline Parameters & Value \\
\hline Particle diameter & $60 \mu \mathrm{m}$ \\
\hline Density of particles & $5150 \mathrm{~kg} / \mathrm{m}^{3}$ \\
\hline Material in primary phase & Air \\
\hline Material in discreet phase & Hematite \\
\hline Discretization scheme & Second-order Upwind \\
\hline Particle inlet boundary condition & Wall, $0.04 \mathrm{~kg} / \mathrm{s}$ \\
\hline Gas inlet boundary condition & Velocity inlet at $2.50 \mathrm{~m} / \mathrm{s}$ \\
\hline Outlet boundary condition & Pressure Outlet \\
\hline Numerical scheme & Phase Coupled Simple \\
\hline Drag model & Syamlal-O'Brien \\
\hline Time step & Fluid: $10^{-3} \mathrm{~s}$ Particle: $10^{-4} \mathrm{~s}$ \\
\hline
\end{tabular}

Figure 4 shows the variation in the mass flow rate with respect to time at the outlet of the reactor. It can be concluded that at the start of the simulation, particles escape the reactor at a discontinuous rate. However, after $28 \mathrm{~s}$, the particles start to escape almost at a continuous rate of $0.0007 \mathrm{~kg} / \mathrm{s}$. This is of the same order as was found in the experiment performed by Haider et al. [22]. The stable circulation of hematite is achieved, which shows it can be used as an OC. 


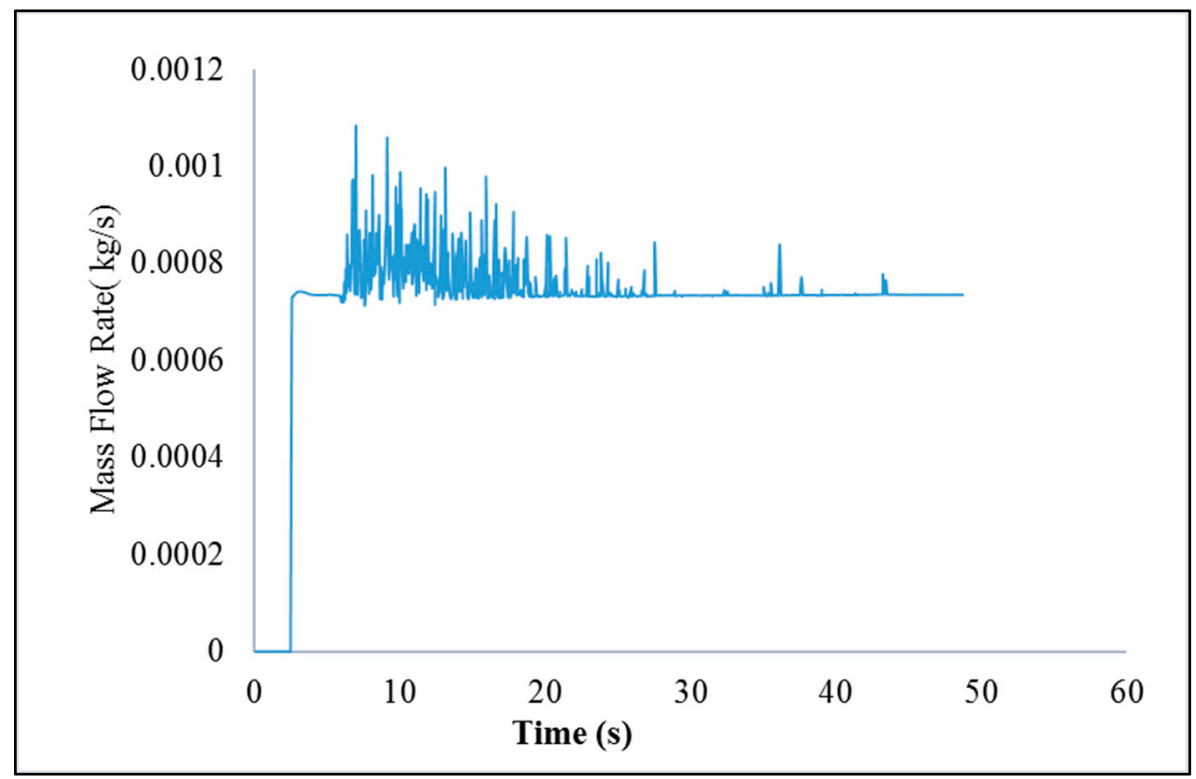

Figure 4. Variation of mass flow rate with respect to time at the outlet of the reactor.

Figure 5 shows the variation in static pressure (gauge) with time at different heights in the reactor. This is an important study because it is the pressure difference of the particles at the inlet and outlet that drives them into the reactor. It is evident from the graph that the pressure at the mixture outlet is zero, while the pressure inside the reactor after $15 \mathrm{~s}$ is almost $1.5 \mathrm{kPa}$ at any height. Since the height of the particle bed is much lower compared to the height of the reactor, the pressure differences along the height are almost the same. It is also noticeable from the figure that up to $2 \mathrm{~s}$, the pressure inside the reactor is also zero, because the particles are settling on the bed during this period in the reactor. After the settling period is over, an instantaneous spike in pressure can be seen, the magnitude of which is different at different heights. This is because when the air is injected through the bed, at that moment, it experiences the resistance from the particle bed. The magnitude of the pressure spike is its highest $(6.2 \mathrm{kPa})$ at air inlet and its lowest $(1.9 \mathrm{kPa})$ at the top of the reactor for a $7 \mathrm{~m}$ height. The particle inside the bed begins to move upward as a result of this pressure buildup. The bed stabilizes after $15 \mathrm{~s}$ when the fast fluidization regime is fully developed.

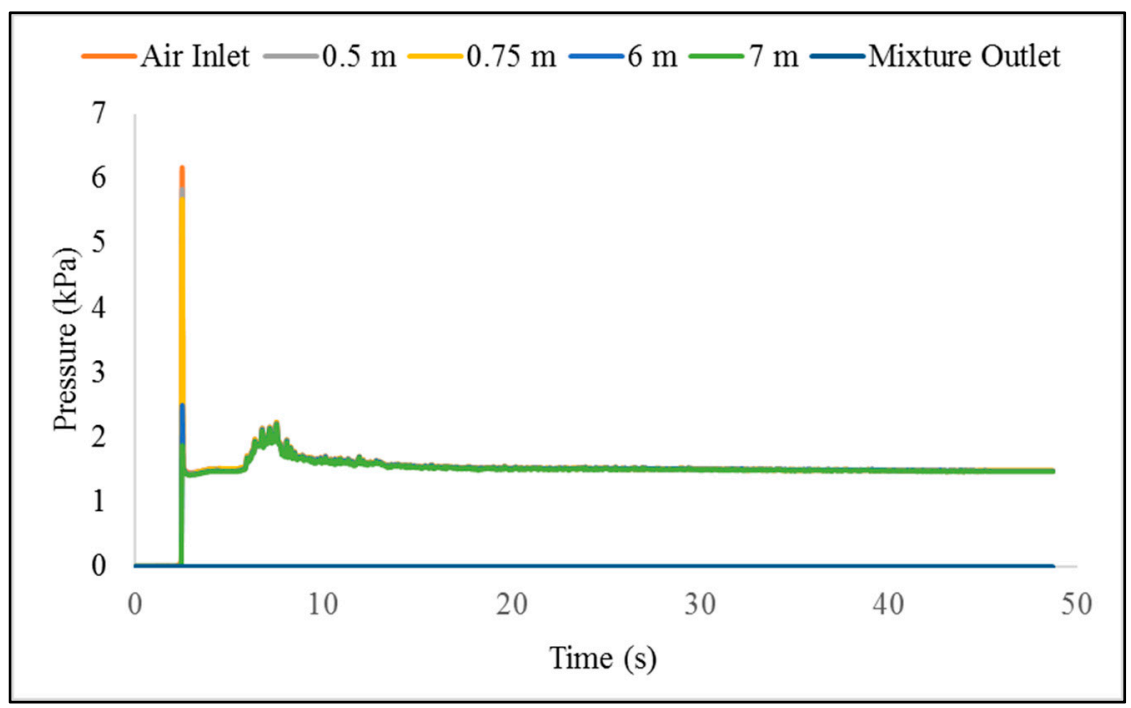

Figure 5. Variation of static pressure with time at different heights. 
The particle volume fraction is an important parameter because it helps to understand the fractional distribution of the solid particle at different heights during different time intervals. The volume fraction of solid particles with respect to time at different heights is shown in Figure 6. The volume fraction of solids is much lower because of the small volume occupied by them, as compared to the volume of the reactor. However, the surge in volume fraction is noticed initially at a height of $0.5 \mathrm{~m}$ and $0.75 \mathrm{~m}$. The maximum volume fraction is observed at a height of $0.5 \mathrm{~m}$ at $2 \mathrm{~s}$. This happens because of the gathering of the particles at the bottom planes of the reactor, as a result of particle movement. The particle volume fraction at higher planes is not affected at that instant due to the small number of particles transferred from the bottom. A stable particle distribution is observed after $28 \mathrm{~s}$ when the oscillations in volume fraction are reduced.

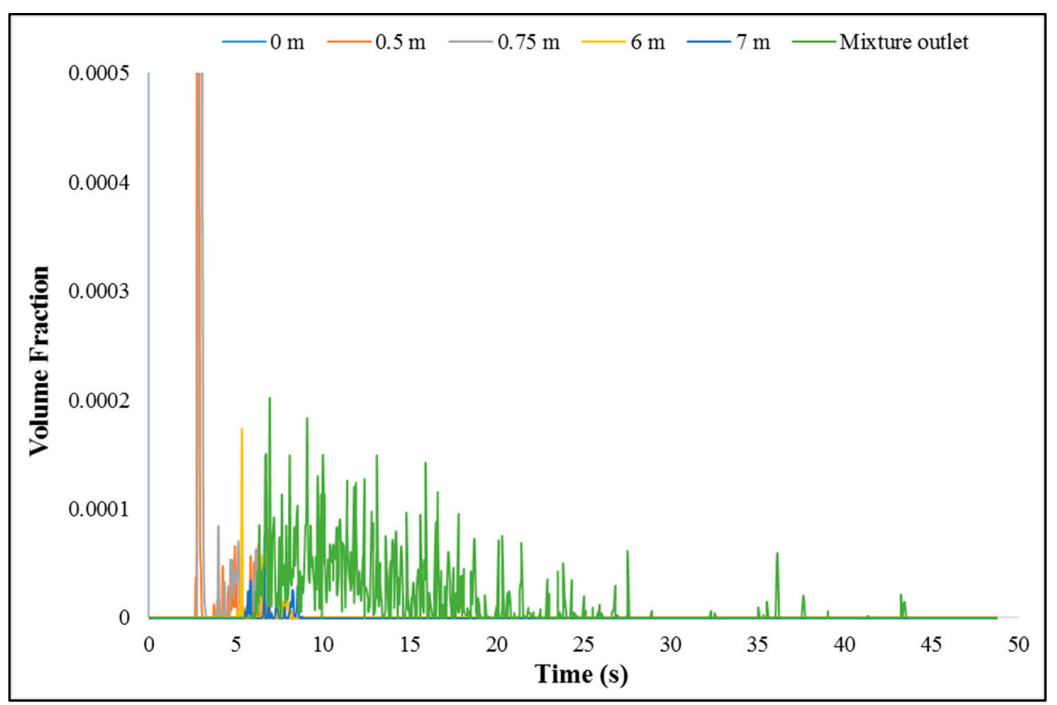

Figure 6. Variation in volume fraction with time at different heights.

The velocity of the gas phase (air) plays an important role in fluidizing the bed as well as lifting the particles from the bed to the outlet. Figure 7 shows the transient variation in air velocity along different heights of the reactor.

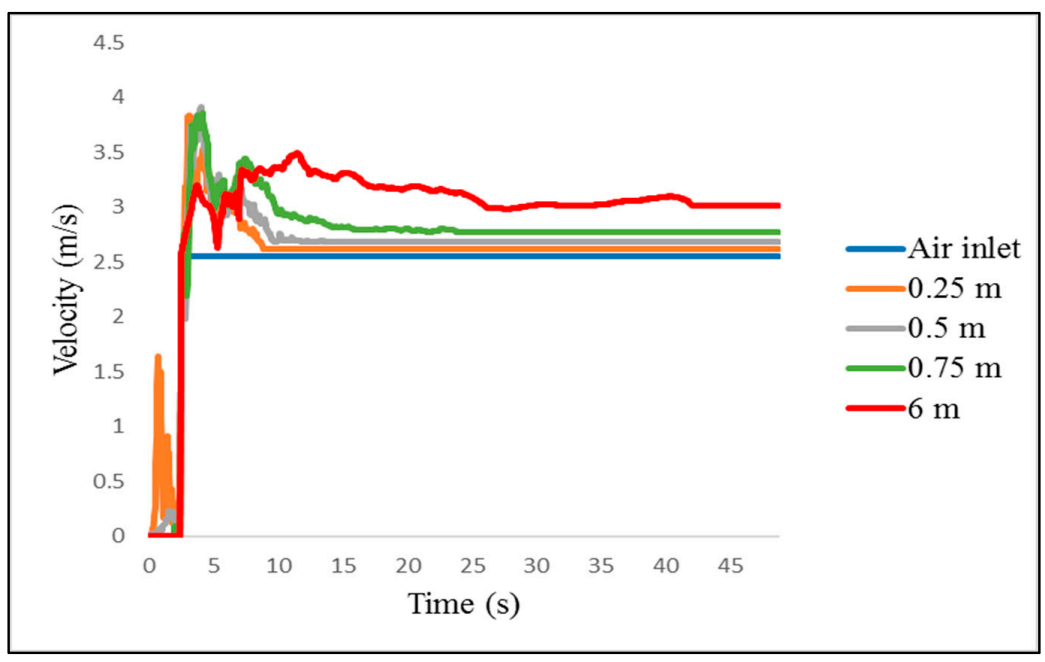

Figure 7. Variation in air velocity with time at different heights.

It can be observed from the graph that the initial velocity of air at the air inlet is 0 and after $2 \mathrm{~s}$ it is $2.5 \mathrm{~m} / \mathrm{s}$, according to the boundary condition. The velocity of air at a height of $0.25 \mathrm{~m}$ increases due to the internal turbulence created by the particles injected 
into the reactor for $1 \mathrm{sec}$. However, this decreases as the particles get settled down at the bed. As the bed settles and the velocity of air at the inlet is increased gradually up to the terminal velocity, there is a sudden spike in the velocity, which can be seen in the graph along with the different heights of the reactor. This happens because of the turbulence created by the particle and the increasing air velocity at the inlet. However, once stable circulation is achieved, the velocity becomes constant to maintain the continuous flow of the particles to the outside.

Figure 8 gives the particle velocity profile at different heights of the reactor with time. The velocity of the particles depends on the air velocity from the bottom of the reactor. Initially, the particle velocity is zero at all the heights of the reactor, but it gradually increases with the increment in the air velocity. The maximum variation in the velocity is observed at the outlet of the reactor. At the outlet of the reactor, the particles attain the maximum velocity of $13.74 \mathrm{~m} / \mathrm{s}$ because of the decreased area of the outlet pipes. However, this decreases as the number of particles inside the reactor decreases.

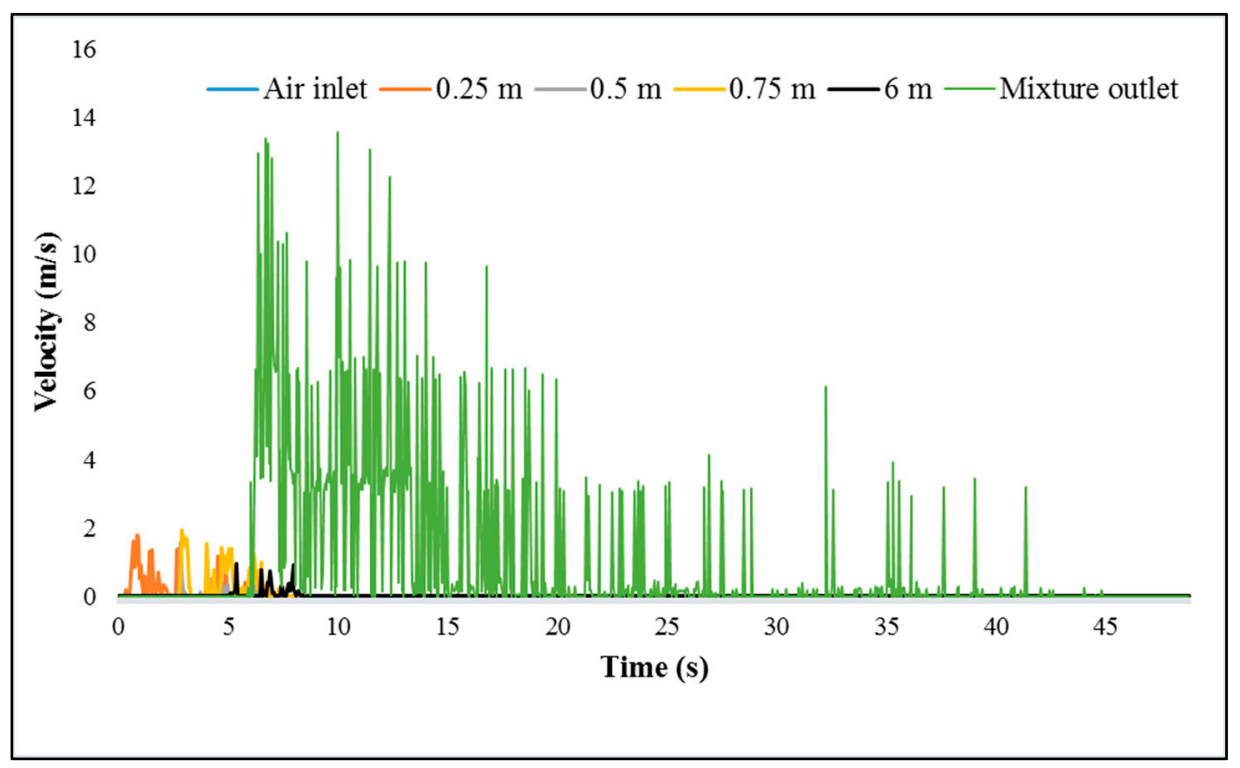

Figure 8. Variation in particle velocity with time at different heights.

For the validation, the simulation with FE100 replacing hematite as the OC has now been carried out, and the values of static pressure at different heights are compared with the experimental values presented in Haider et al. [22] The parameters including reactor geometry, the diameter of $\mathrm{OC}$, maximum fluidization velocity, etc., are taken from the data available in the experimental work [22].

Figure 9 shows the comparison of experimental and numerical data of static pressure at various heights. It can be observed that the graphs of static pressure are almost of the same magnitude at different heights, except for the difference at the inlet. This difference occurs because of the different initial processes of the simulation and experimental work. In the experiment, the particles are injected from the narrow tube thoroughly. On the other hand, in the simulation, the particles are considered to be injected from some height of the reactor, and they are then left for $1 \mathrm{~s}$ to settle before the air injection. Changing the drag law can also help in minimizing the deviation of numerical results from the experimental result [32]. The decay in static pressure after the inlet is found to be consistent with the experimental results, along with the height of the reactor. Figure 10 shows the error bar graph for the difference between experimental and numerical data. It can be seen from the graph that the errors are much smaller at any height, except at the inlet. 


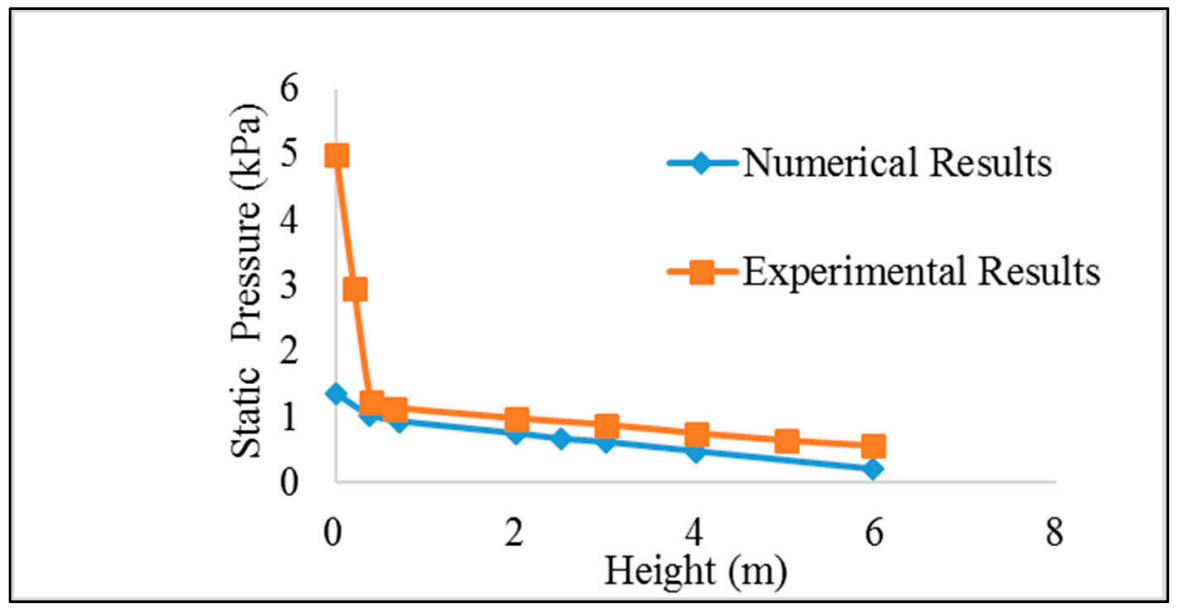

Figure 9. Comparison of numerical and experimental data of static pressure at various heights.

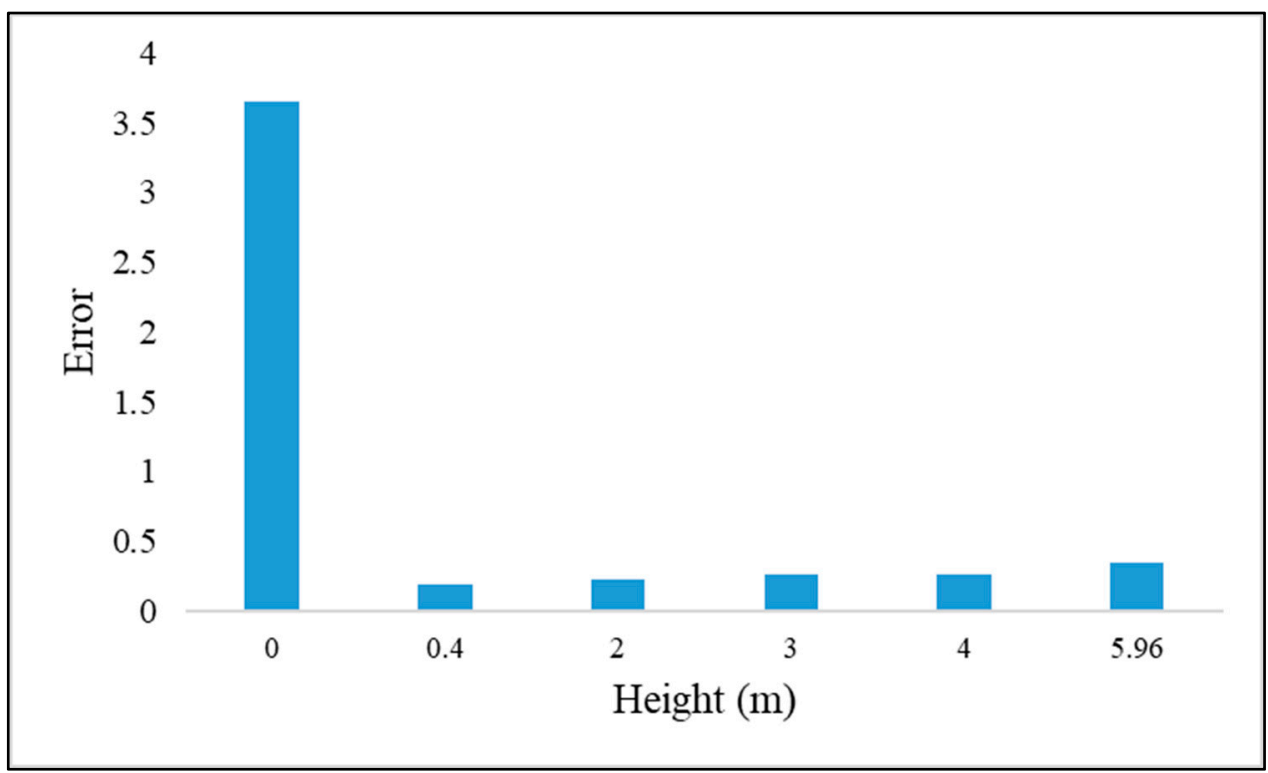

Figure 10. Error bar graph for experimental and numerical data.

\section{Conclusions}

In this work, the DDPM model of Ansys Fluent 17 was used to carry out a cold flow simulation of the fast-fluidized bed air reactor with hematite as the OC for CLC. A proper particle distribution and mass flow rate of the circulating $\mathrm{OC}$ are necessary in order to achieve stable circulating conditions. The mass flow rate and volume fraction of the particle stabilizes after $28 \mathrm{~s}$ at the particle outlet, and a constant pressure gradient of $1.5 \mathrm{kPa}$ is maintained between the inlet and outlet of the reactor after $15 \mathrm{~s}$ of particle injection. The results are validated by comparing the variation in static pressure along the height of the reactor with the experimental work performed by Haider et al. [22] at Cranfield, UK, considering FE100 as the OC. On this basis, it can be concluded that the DDPM model is suitable for determining the hydrodynamics of a fast-fluidized bed reactor, and hematite can be opted as the OC for CLC due to its capacity for fast oxidation and reduction during the combustion process.

Author Contributions: Conceptualization, P.K. and A.K.P.; methodology, P.K. and A.K.P.; software, A.K.P. and V.V.; validation, P.K. and V.V.; formal analysis, P.K. and V.V.; investigation, P.K.; resources, A.K.P. and V.V.; data curation, A.K.P. and D.K.G.; writing-original draft preparation, P.K.; writingreview and editing, A.K.P., D.K.G. and V.V.; visualization, P.K. and V.V.; supervision, A.K.P. and V.V.; 
project administration, A.K.P.; funding acquisition, D.K.G. and A.K.P. All authors have read and agreed to the published version of the manuscript.

Funding: Not Applicable.

Institutional Review Board Statement: Not Applicable.

Informed Consent Statement: Not Applicable.

Data Availability Statement: The data cited in this manuscript are available from the published papers or a corresponding author.

Conflicts of Interest: The authors declare no conflict of interest.

\section{References}

1. Mauna Loa Observatory Hawaii. Measurements of the Concentration of Carbon Dioxide. Available online: https://www.co2 .earth/daily-co2 (accessed on 31 January 2021).

2. CEA. All India Installed Capacity (in MW) of Power Stations. CEA Report January 2020. Available online: http://cea.nic.in/ reports/monthly/installedcapacity/2020/installed_capacity-01.pdf (accessed on 20 December 2020).

3. A report published by ZEP. A European Technology and Innovation Platform (ETIP) under the Commission's Strategic Energy Technologies Plan. Available online: https:/ / zeroemissionsplatform.eu/about-ccs-ccu/what-is-ccs/co2-capture/ (accessed on 18 December 2020).

4. Carbon Monitoring for Action. Report Published by Centre for Global Development. 2017. Available online: https://www.cgdev. $\mathrm{org} /$ topics / carbon-monitoring-action (accessed on 20 November 2020).

5. Ishida, M.; Jin, H. A novel chemical-looping combustor without NOx formation. Ind. Eng. Chem. Res. 1996, 35, $2469-2472$. [CrossRef]

6. Cuadrat, A.; Abad, A.; García, L.F.; Gayán, P.; de Diego, L.F.; Adánez, J. Relevance of the coal rank on the performance of the in situ gasification chemical-looping combustion. Chem. Eng. J. 2012, 195, 91-102. [CrossRef]

7. Leion, H.; Mattisson, T.; Lyngfelt, A. Solid fuels in chemical-looping combustion. Int. J. Greenh. Gas. Cont. 2008, 2, 180-193. [CrossRef]

8. Lu, H.; Gidaspow, D.; Bouillard, J.; Wentie, L. Hydrodynamic simulation of gas-solid flow in a riser using kinetic theory of granular flow. Chem. Eng. J. 2003, 95, 1-13.

9. Abad, A.; García-Labiano, F.; de Diego, L.F.; Gayán, P.; Adánez, J. Reduction kinetics of Cu-, Ni-, and Fe-based oxygen carriers using syngas $(\mathrm{CO}+\mathrm{H} 2)$ for chemical-looping combustion. Energy Fuels 2007, 21, 1843-1853. [CrossRef]

10. Jung, J.; Gamwo, I.K. Multiphase CFD-based models for chemical looping combustion process: Fuel reactor modeling. Powder Technol. 2008, 183, 401-409. [CrossRef]

11. Wang, X.F.; Jin, B.S.; Zhong, W.Q. Three-dimensional simulation of fluidized bed coal gasification. Chem. Eng. Process. 2009, 48, 695-705. [CrossRef]

12. Chen, X.Z.; Shi, D.P.; Gao, X.; Luo, Z.H. A fundamental CFD study of the gas-solid flow field in fluidized bed polymerization reactors. Powder Technol. 2011, 205, 276-288. [CrossRef]

13. Su, M.Z.; Zhao, H.B.; Ma, J.C. Computational fluid dynamics simulation for chemical looping combustion of coal in a dual circulation fluidized bed. Energy Convers. Manag. 2015, 105, 1-12. [CrossRef]

14. Deng, Z.Y.; Xiao, R.; Jin, B.S.; Song, Q.L. Numerical simulation of chemical looping combustion process with CaSO4 oxygen carrier. Int. J. Greenh. Gas. Control. 2009, 3, 368-375. [CrossRef]

15. Parker, J.M. CFD model for the simulation of chemical looping combustion. Powder Technol. 2014, 265, 47-53. [CrossRef]

16. Han, L.; Bollas, G.M. Dynamic optimization of fixed bed chemical-looping combustion processes. Energy 2016, 112, 1107-1119. [CrossRef]

17. Zhang, Y.W.; Chao, Z.X.; Hugo, A.J. Modelling and simulation of chemical looping combustion process in a double loop circulating fluidized bed reactor. Chem. Eng. J. 2017, 320, 271-282. [CrossRef]

18. Haus, J.; Hartge, E.U.; Heinrich, S.; Werther, J. Dynamic flowsheet simulation for chemical looping combustion of methane. Int J. Greenh. Gas. Control. 2018, 72, 26-37. [CrossRef]

19. Hamidouche, Z.; Masi, E.; Fede, P.; Simonin, O.; Mayer, K.; Penthor, S. Unsteady three-dimensional theoretical model and numerical simulation of a 120-kW chemical looping combustion pilot plant. Chem. Eng. Sci. 2019, 193, 102-119. [CrossRef]

20. Arjmand, M.; Leion, H.; Mattisson, T.; Lyngfelt, A. Investigation of different manganese ores as oxygen carriers in chemicallooping combustion (CLC) for solid fuels. Appl. Energy 2014, 113, 1883-1894. [CrossRef]

21. Menon, K.G.; Patnaikuni, V.S. CFD simulation of fuel reactor for chemical looping combustion of Indian coal. Fuel. 2017, 203, 90-101. [CrossRef]

22. Haider, S.K.; Duan, L.; Patchigolla, K.; Anthony, E. A hydrodynamic study of a fast-bed dual circulating fluidized bed for chemical looping combustion. Energy Technol. 2016, 4, 1254-1262. [CrossRef]

23. Singh, R.I.; Brink, A.; Hupa, M. CFD modeling to study fluidized bed combustion and gasification. App. Therm. Eng. 2013, 52, 585-614. [CrossRef] 
24. Shuai, W.; Guodong, L.; Huilin, L.; Juhui, C.; Yurong, H.; Jiaxing, W. Fluid dynamic simulation in a chemical looping combustion with two interconnected fluidized beds. Fuel Process. Technol. 2011, 92, 385-393. [CrossRef]

25. Hamidouche, Z.; Ku, X.; Lin, J.; Wang, J. Numerical simulation of a chemical looping combustion of biomass: Hydrodynamic investigation. Fuel Process. Technol. 2020, 207, 106486. [CrossRef]

26. Fan, F.; Zhang, M.; Peng, Z.; Chen, J.; Su, M.; Moghtaderi, B.; Doroodchi, E. Direct Simulation Monte Carlo Method for Acoustic Agglomeration under Standing Wave Condition. Aerosol Air Qual. Res. 2017, 17, 1073-1083. [CrossRef]

27. Mahalatkar, K.; Kuhlman, J.; Huckaby, E.D.; O’Brien, D. CFD Simulation of a chemical looping fuel reactor utilizing solid fuel. Chem. Eng. Sci. 2011, 66, 3617-3627. [CrossRef]

28. Yang, M.; Banerjee, S.; Agarwal, R.K. Transient Cold Flow Simulation of Fast Fluidized Bed Fuel Reactors for Chemical-Looping Combustion. ASME J. Energy Resour. Technol. 2018, 140. [CrossRef]

29. Syamlal, M.; O'Brien, T. Computer simulation of bubbles in a fluidized bed. AIChE Symp. Ser. 1989, 85, $22-31$.

30. Peng, Z.; Doroodchi, E.; Alghamdi, Y.; Moghtaderi, B. Mixing and segregation of solid mixtures in bubbling fluidized beds under conditions pertinent to the fuel reactor of a chemical looping system. Powder Technol. 2013, 235, 823-837. [CrossRef]

31. Peng, Z.; Doroodchi, E.; Alghamdi, Y.A.; Shah, K.; Luo, C.; Moghtaderi, B. CFD-DEM simulation of solid circulation rate in the cold flow model of chemical looping systems. Chem. Eng. Res. Design. 2015, 95, 262-280. [CrossRef]

32. Peng, Z.; Alghamdi, Y.A.; Moghtaderi, B.; Doroodchi, E. CFD-DEM investigation of transition from segregation to mixing of binary solids in gas fluidised beds. Adv. Powder Technol. 2016, 27, 2342-2353. [CrossRef] 